\title{
Structural durability assessment of welded offshore K-nodes by different local design concepts
}

\author{
C.M. Sonsino \\ Fraunhofer Institute for Structural Durability and System Reliability LBF, Darmstadt, Germany; c.m.sonsino@lbffraunhofer.de
}

ABSTRACT. The structural durability design of complex welded structures should not rely only on one single design method but should apply different methods for assuring the reliability of the assessment. In this context the application of the structural stress concept, notch stress concept and crack propagation concept are discussed through the example of $\mathrm{K}$-nodes used in energetic offshore constructions like oil platforms or wind power plants, presenting the state of the art.

KEYWORDS. Welded joints; Steel; Design concept.

\section{INTRODUCTION}

7 he most important parameters controlling the durability of welded structures are the service loadings, mechanical as well as environmental, the geometry to be realized according to the required service function, the material and the manufacturing process, Fig. 1 [1]. These interactive parameters are matched together by reliability and safety concepts while in this paper, the relation between reliability and safety in fatigue design, Fig. 2, will be highlighted through the example of $\mathrm{K}$-nodes used in energetic offshore constructions, Fig. 3 and 4.

\section{DESIGN CONCEPTS FOR OFFSHORE K-NODES AND PREREQUISITES}

he most commonly applied fatigue design concepts [2] for the assessment of welded joints, are displayed in Fig. 5. Design prerequisites for evaluating the durability of K-nodes, such as geometry, spectrum, experimental results, allowable stress ranges, fracture mechanics data, FE-model, and the FE-calculation of hot-spot and notch stresses, will be presented. After this, the evaluation of the experimental results by selected concepts will be carried out.

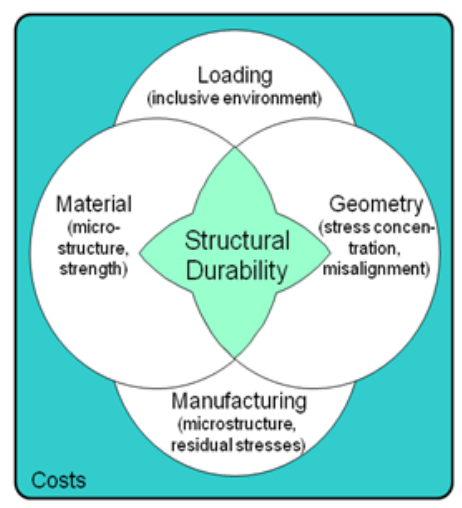

Figure 1: Influencing parameters of durability of welded structures. 


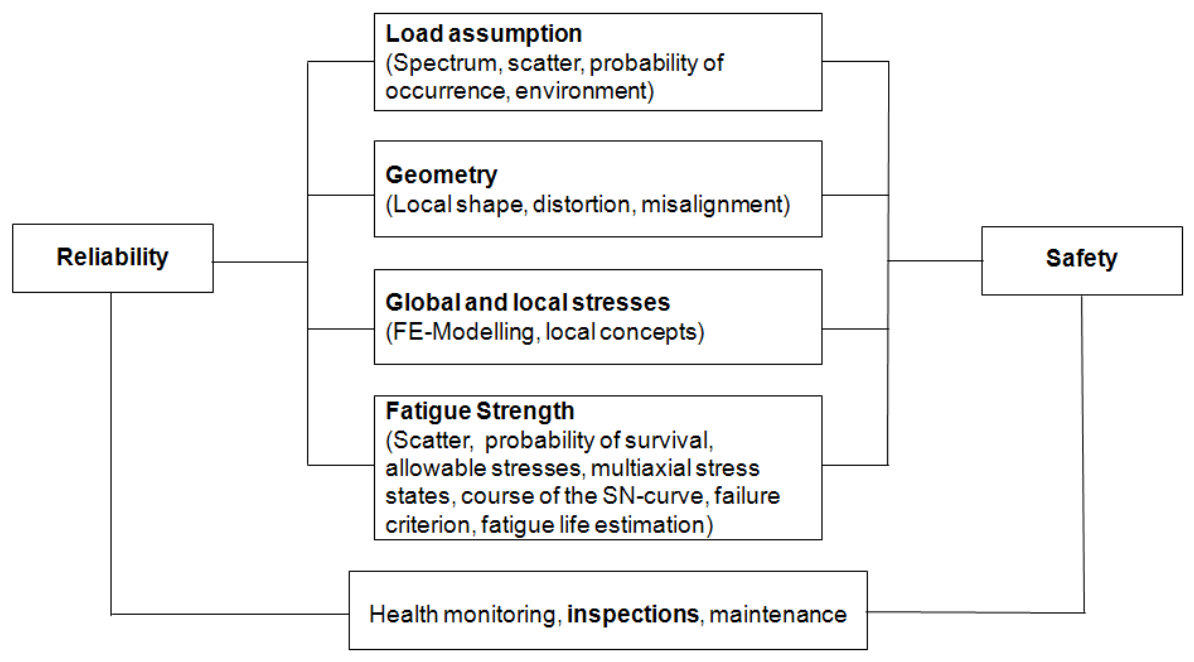

Figure 2: Reliability and safety aspects in fatigue design.
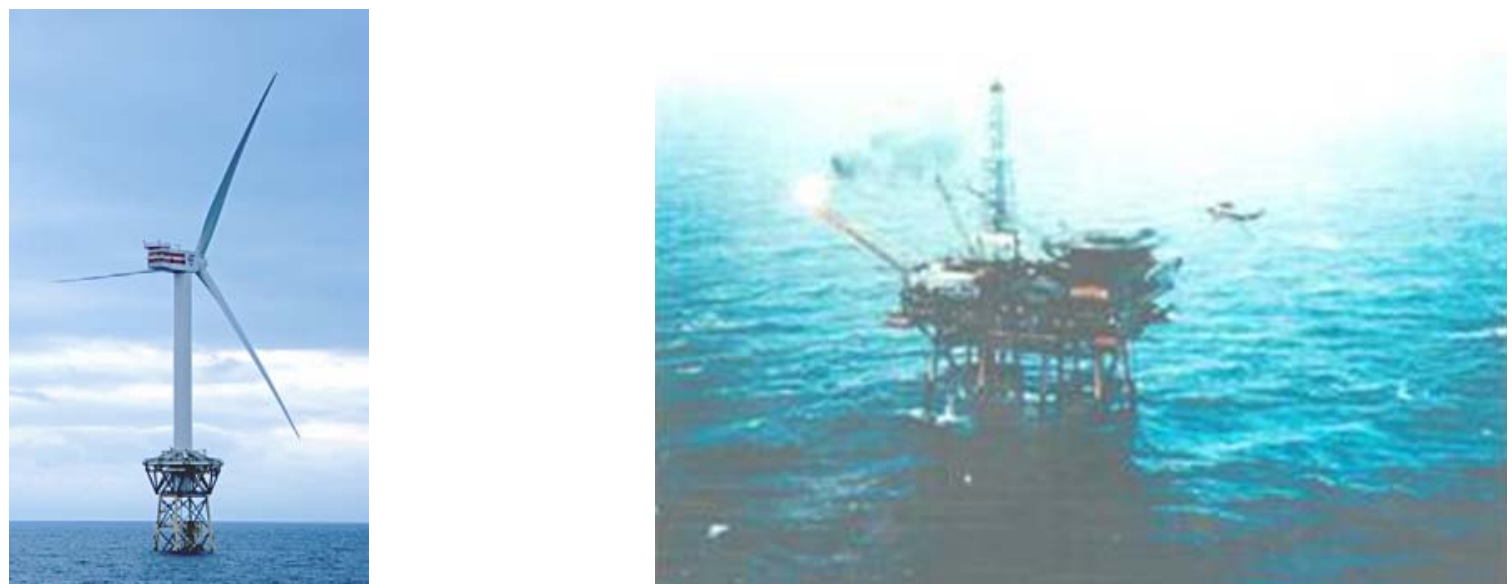

Figure 3: Offshore wind power plant (REpower Systems AG).

Figure 4: Offshore oil platform.

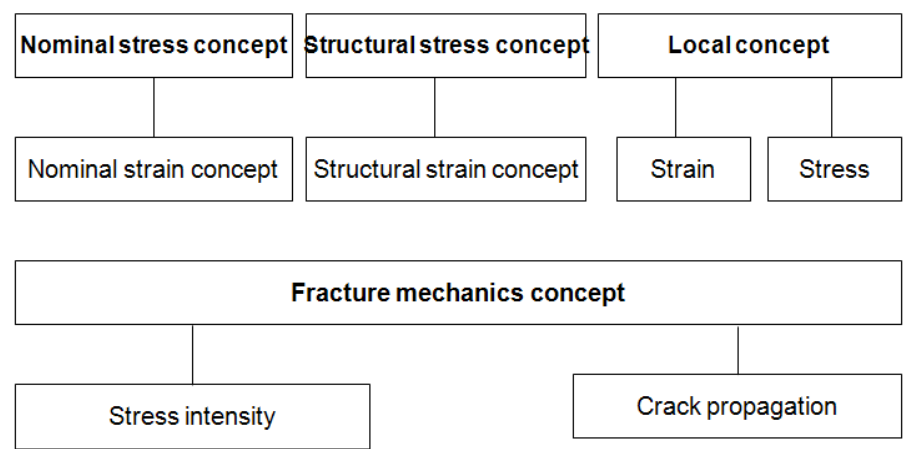

Figure 5: Overview of fatigue design concepts for welded joints.

As for the fatigue critical areas of the K-nodes, Fig. 6, at the chord-sided weld seam a nominal stress cannot be defined and as the notch strain concept is not yet sufficiently mature for application, only the hot-spot stress concept, the notch stress concept and the crack propagation concept will be compared, based on experimental results obtained with gas metal arc welded K-nodes, Fig. 6, from the fine grained structural steel Fe 355 [3]. The tests were carried out under constant and variable amplitude loading under artificial sea-water. The straight line spectrum for variable amplitude loading (Common 
Load Sequence, COLOS) was derived from sea-state observations in the North Sea. One sequence with the size $\mathrm{L}_{\mathrm{s}}=4.95$ $\mathrm{x} 10^{5}$ cycles corresponds to one year of service, Fig. 7.

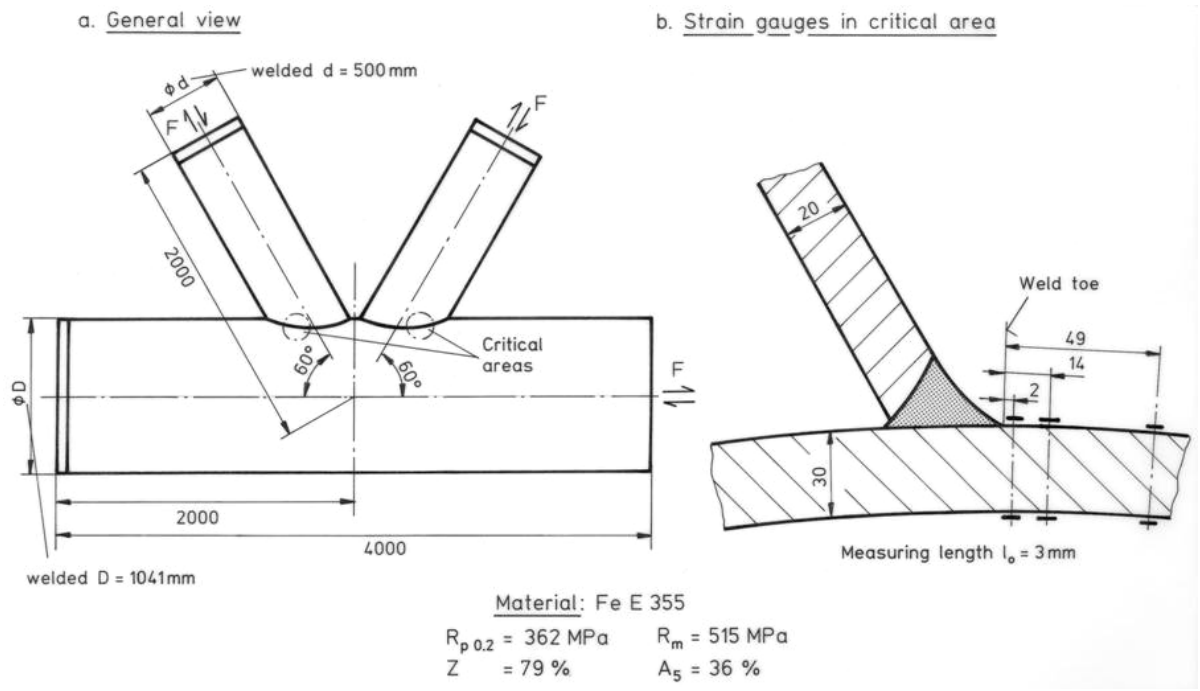

Figure 6: Geometry of welded K-nodes.

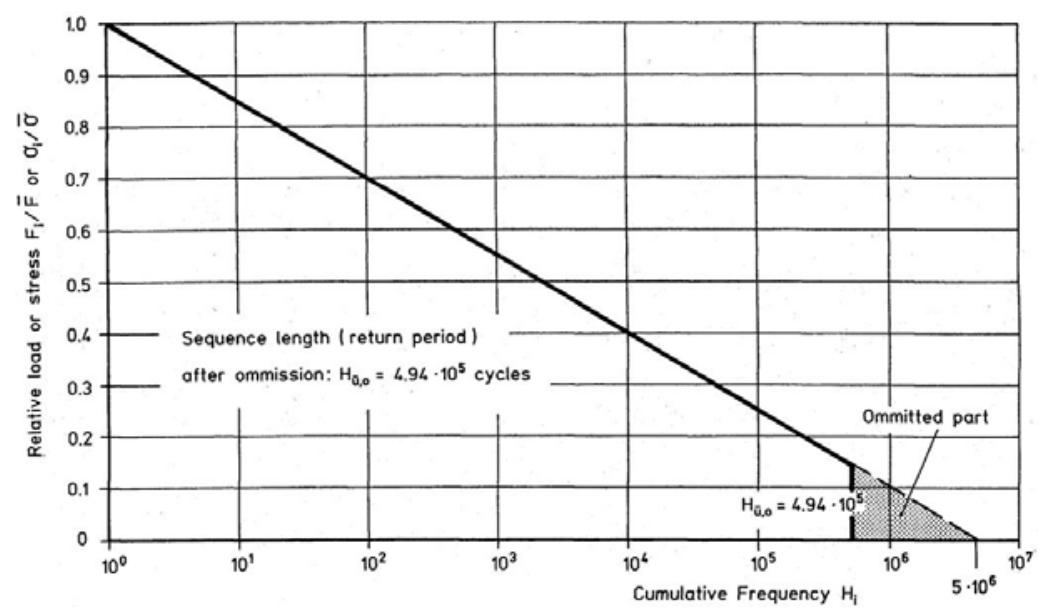

Figure 7: Colos spectrum.

All of the tested tubulars were instrumented in the critical areas with strain gauges and two failure criteria were defined for presentation of the test results: Fatigue life to the initiation of a crack with a depth of a $\approx 1.00 \mathrm{~mm}$, detected by DC potential drop technique, and the fatigue life to break-through, Fig. 8. Crack propagation between these two incidents was also registered.

The nominal stress range on the ordinate of Fig. 8 is valid only for the braces of the K-nodes and not related to the chord side of the weld seams. As the failures occure on the chord side, for which a nominal stress cannot be defined, the nominal stress concept is not applicable for the assessment of the investigated K-nodes. The calculations of the hot-spot and notch stress ranges will be explained later.

Fig. 8 includes, as well as the mean curves with the probability of survival $\mathrm{P}_{\mathrm{s}}=50 \%$ for the break-through criterion, also the fatigue life curve for variable amplitude loading with $P_{s}=97.7 \%$, which is the assigned probability to fatigue life curves in the IIW-recommendations [4]. This curve is obtained by reducing the mean curve by the factor of $j=1.37$ resulting from the assumed scatter $T_{\sigma}=1: 1.50$ and a Gaussian log-normal distribution.

For assessment of the accuracy of the hot-spot and local concepts, the IIW-design curves (allowable stresses) FAT 90 and FAT $225\left(\mathrm{P}_{\mathrm{s}}=97.7 \%\right)$ were used. The curves were corrected for thickness and the sea-water corrosion was considered according to GL-design rules [5]. In the case of the local stress concept, as the load dependent notch stresses were 
calculated for the reference radius $\mathrm{r}_{\mathrm{ref}}=1.00 \mathrm{~mm}$, Fig. 9, according to von Mises, the FAT value $225 \mathrm{MPa}$, which is a principal stress, was transformed into a von Mises stress of $200 \mathrm{MPa}$ [6], Tab. 1. This table contains also allowable values for the reference radius $\mathrm{r}_{\mathrm{ref}}=0.05 \mathrm{~mm}$ to be applied for thin sheets with $\mathrm{t}<5 \mathrm{~mm}$.

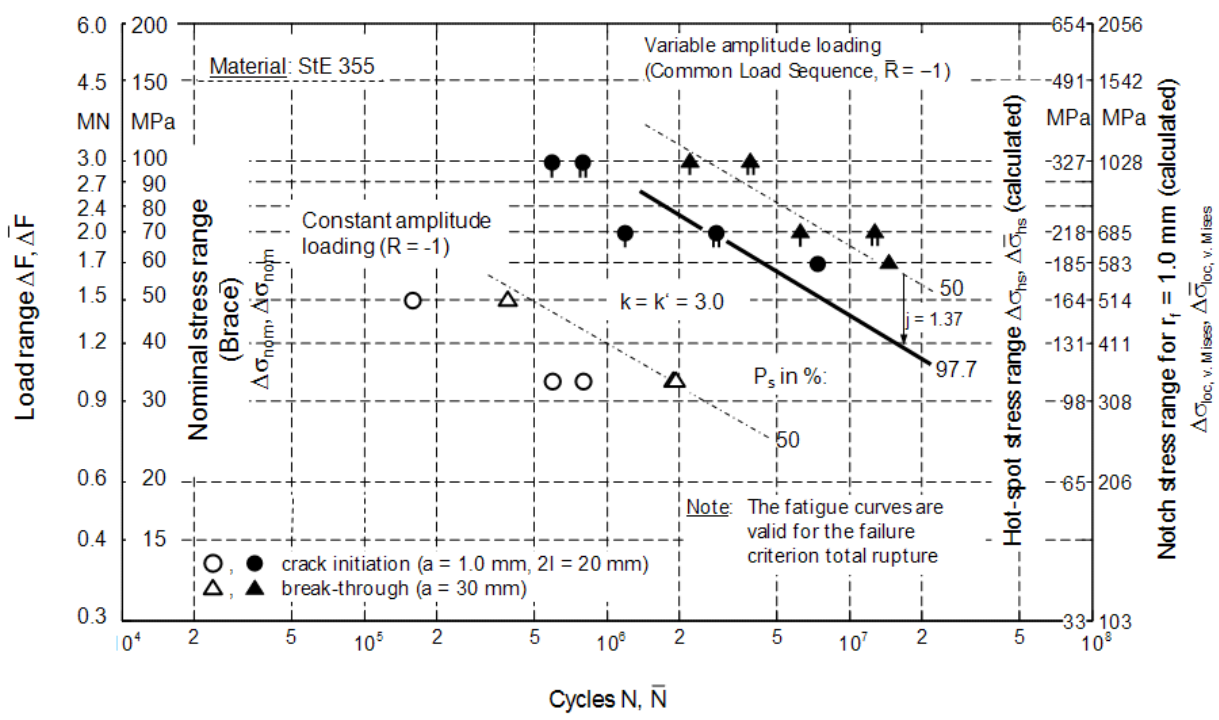

Figure 8: Results presented by load ranges versus fatigue life.

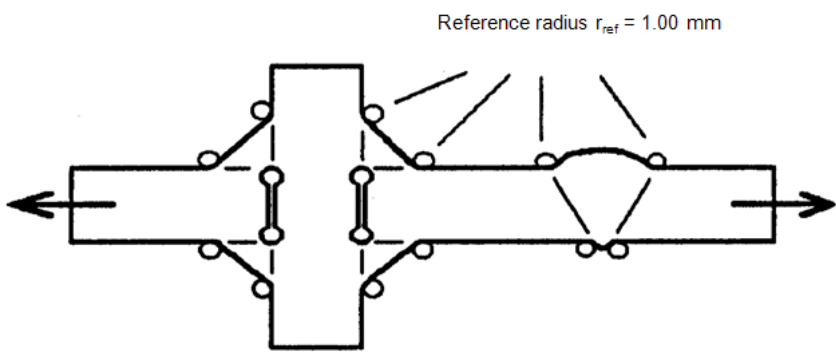

Figure 9: Principle of applying reference radii.

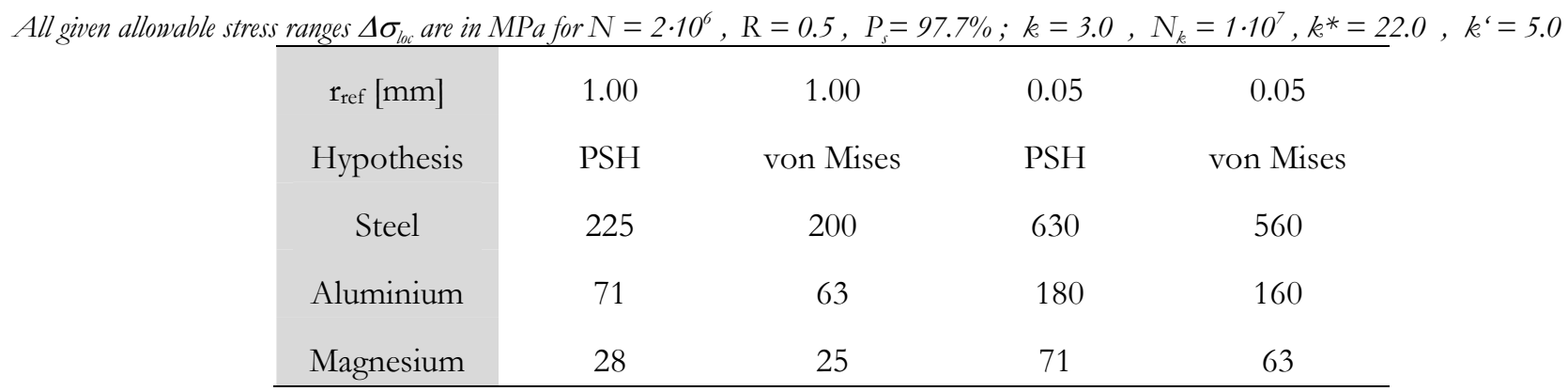

Table 1: FAT-values according to the notch stress concept for different reference radii and strength hypotheses (PSH: Principal stress hypothesis).

With regard to cumulative damage, Fig. 10, the fatigue life assessment for spectrum loading was carried out according to the Palmgren-Miner Rule keeping the slope $\mathrm{k}^{\prime}=\mathrm{k}$ after the knee point [7] and using the allowable damage sum $\mathrm{D}_{\text {al }}=0.5$ [8].

For the crack propagation calculations, the Paris-Erdogan curve for steel in salt water with $\mathrm{R}=0$ and $\mathrm{P}_{\mathrm{s}}=50 \%$, Fig. 11, was used. 


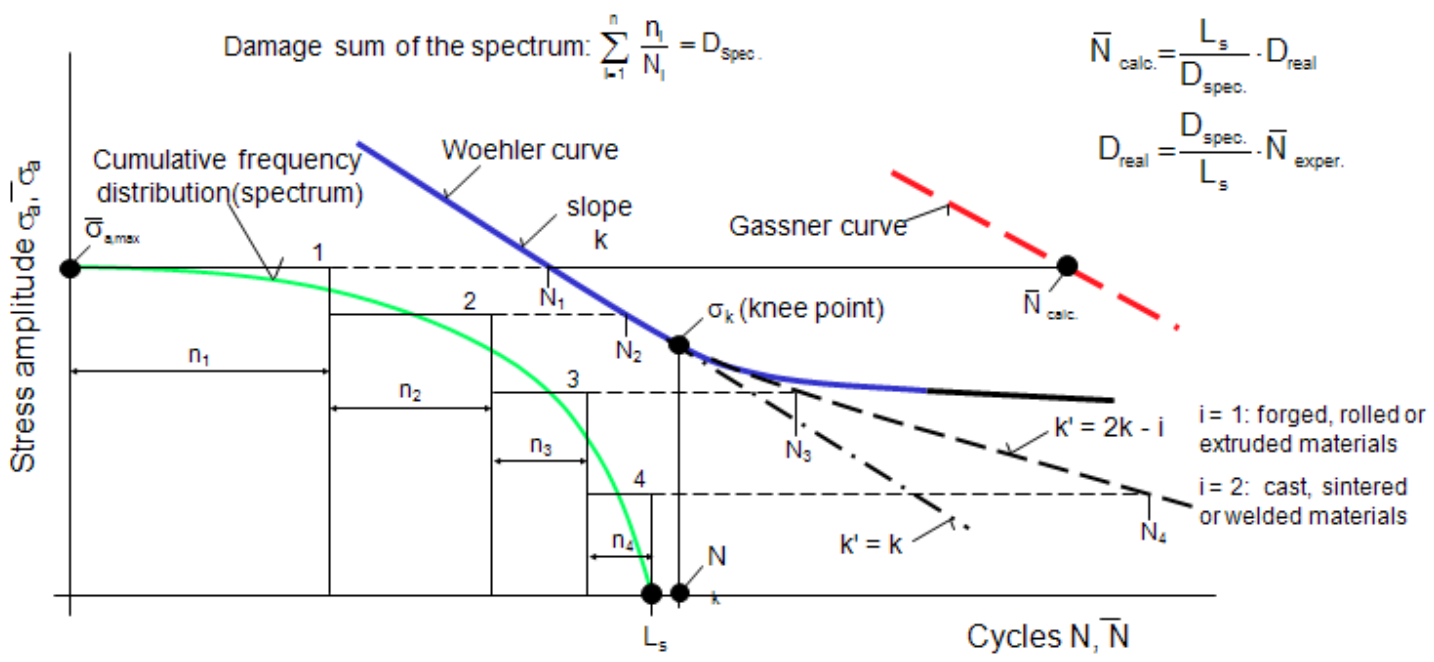

Figure 10: Modification of the SN-curve and calculation of fatigue life (schematically).

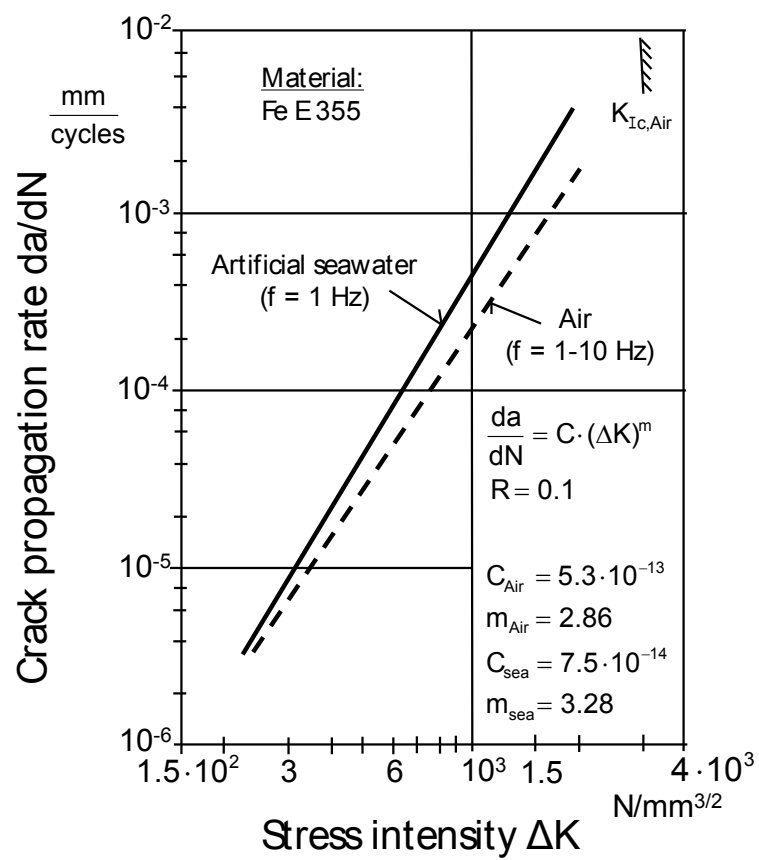

Figure 11: Crack propagation law for steel in air and seawater.

The crack propagation calculations were carried out using the single edge model, Fig. 12. The effect of possible tensile residual stresses was covered conservatively using the crack propagation data with $\mathrm{R}=0$ [9] even though the tests were carried out with $\mathrm{R}=-1$.

The FE-modelling of the critical area of the brace-chord connection was carried out to determine the hot-spot stresses and the modelling of the weld toe for the calculation of the local stresses for the reference radii $r_{\text {ref }}=0.5$ and $1.00 \mathrm{~mm}$, Fig. 13.

The hot-spot stress (von Mises) was calculated for the critical crack initiation region $\left(\varphi=105^{\circ}\right)$ by a FE-Model in the program system MARC using curved four-node "thick" shell elements. The stiffening effect of the weld seam on chord wall bending itself was not modelled. The notch stress was calculated by a plane cross sectional model (in finite elements) subject to prescribed end displacements (including end notations) taken from the three dimensional tubular joint model. The linear-elastic stress was determined for the plane strain condition for measured minimum weld toe radius of $\mathrm{r}=0.5$ 
$\mathrm{mm}$ with the flank angle $\Theta=45^{\circ}$ as well as for the reference radius of $\mathrm{r}_{\mathrm{ref}}=1.00 \mathrm{~mm}$. Principal stresses, as well as appertaining von Mises stresses $\left(\sigma_{\text {eq, }}\right.$ von Mises $\left.=0.89 \times \sigma_{1}\right)$, are given in Fig. 13 [10].

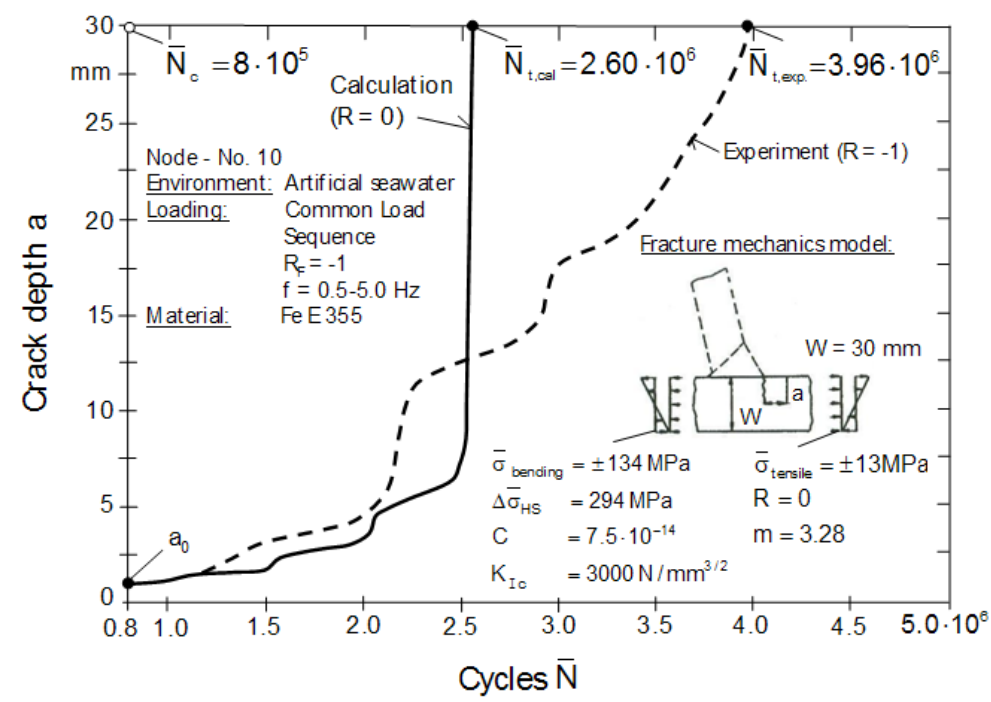

Figure 12: Crack propagation in the chord of a K-node.

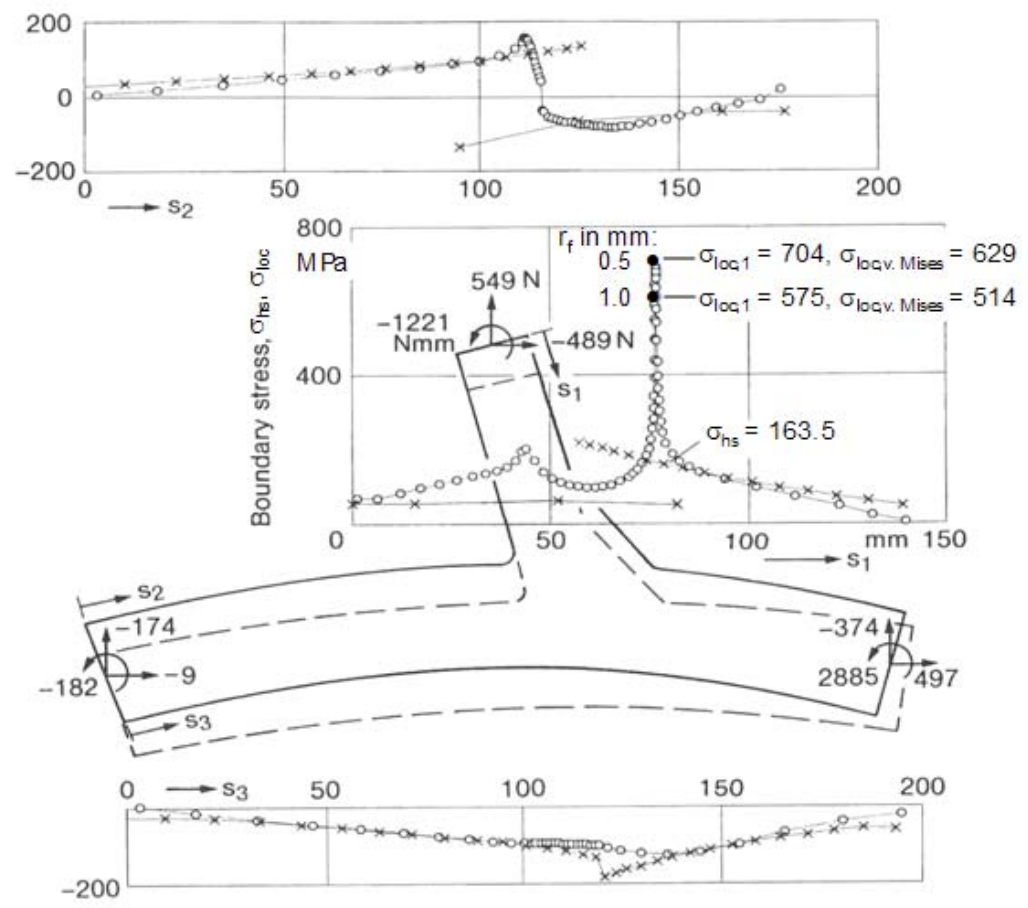

$\mathrm{F}=1.5 \mathrm{M} \mathrm{N}$

Figure 13: Hot-spot and weld local notch stresses in the critical area of the weld seam.

The accuracy of the notch stress cannot be verified by strain measurements whereas that of the hot-spot stresses can. In Table 2, calculated and measured values are compared. The calculated stresses differ from the measured ones within a range of $\pm 15 \%$. The differences result from manufacturing dependent inaccuracies from the ideal geometry assumed for the calculations. Thus, the modelling can be considered as reliable. With regard to modelling of welded structures for application of the hot-spot and local stress concepts also the IIW-Recommendations [4] and the appertaining guidelines [11] should be taken into consideration. 
CA: Constant amplitude loading, VA V ariable amplitude loading

*) retested run-out (brace 1), **) retested run-out (brace 2)

\begin{tabular}{|c|c|c|c|c|c|c|c|c|c|}
\hline \multirow[t]{2}{*}{ No. } & \multirow[t]{2}{*}{$\begin{array}{l}\text { Load } \\
\Delta \mathrm{F} \\
{[\mathrm{MN}]}\end{array}$} & \multirow[t]{2}{*}{$\begin{array}{c}\text { Measured hot- } \\
\text { spot stress } \\
\Delta \sigma_{\mathrm{hs}}[\mathrm{MPa}]\end{array}$} & \multirow{2}{*}{$\begin{array}{c}\text { Local stress } \\
\mathrm{r}_{\mathrm{f}}=1 \mathrm{~mm} \\
\Delta \sigma_{\text {loc.v.Mises }}=3.14 \Delta \sigma_{\mathrm{hs}} \\
{[\mathrm{MPa}]}\end{array}$} & \multirow[t]{2}{*}{$\begin{array}{c}\mathrm{N}_{1} \\
2 \mathrm{a} \approx 1 \mathrm{~mm} \\
2 \mathrm{l} \approx 20 \mathrm{~mm})\end{array}$} & \multirow{2}{*}{$\begin{array}{c}\mathrm{N}_{3} \\
\text { (break- } \\
\text { through) }\end{array}$} & \multicolumn{2}{|c|}{$\begin{array}{l}\text { Site of crack } \\
\text { initiation }\end{array}$} & \multirow[t]{2}{*}{$\begin{array}{l}\text { Calculated } \\
\Delta \sigma_{\mathrm{hs}}[\mathrm{MPa}]\end{array}$} & \multirow{2}{*}{$\begin{array}{c}\text { Calculated } \\
\Delta \sigma_{\text {loc,v.Mises }} \\
{[\mathrm{MPa}]}\end{array}$} \\
\hline & & & & & & $\Psi\left({ }^{\circ}\right)$ & Brace & & \\
\hline $6, \mathrm{CA}$ & 1.5 & 150 & 471 & $1.6010^{5}$ & $3.9510^{5}$ & $\begin{array}{l}90 \\
95\end{array}$ & 1 & 163.5 & 514 \\
\hline $\left.7^{*}\right), \mathrm{CA}$ & 1.0 & 108 & 339 & $6.0010^{5}$ & $1.9210^{6}$ & 105 & 1 & 109 & 343 \\
\hline $7^{* *}, \mathrm{CA}$ & 1.0 & 97 & 305 & $8.0510^{5}$ & $1.9210^{6}$ & 270 & 1 & 109 & 343 \\
\hline 1, VA & 3.0 & 346 & 1086 & $5.9310^{5}$ & $2.2210^{6}$ & 90 & 2 & 327 & 1028 \\
\hline $10, \mathrm{VA}$ & 3.0 & 294 & 920 & $8.0010^{5}$ & $3.9610^{6}$ & 225 & 1 & 327 & 1028 \\
\hline $13, \mathrm{VA}$ & 1.7 & 218 & 685 & $7.4210^{6}$ & $1.4610^{7}$ & 120 & 1 & 185 & 583 \\
\hline $3, \mathrm{VA}$ & 2.0 & 208 & 653 & $2.8210^{6}$ & $1.2910^{7}$ & $\begin{array}{l}235 \\
120 \\
135\end{array}$ & 1,2 & 218 & 685 \\
\hline $2, \mathrm{VA}$ & 2.0 & 205 & 644 & $1.2010^{6}$ & $6.3010^{6}$ & 90 & 1 & 218 & 685 \\
\hline
\end{tabular}

Table 2: Test and calculation results obtained with welded K-nodes.

Assuming the soundness of quality of the welds, of the fatigue data and of the calculated local stresses provided, the comparison of the calculated and experimental fatigue lives will reveal the accuracy and reliability of the three concepts.

\section{COMPARISON OF CALCULATIONS WITH EXPERIMENTS ACCORDING TO SELECTED CONCEPTS}

7 he assessments are carried out with calculated hot-spot and local notch stresses. As the differences between the real and calculated stresses are tolerable, the consideration of the real stresses (which are not known in the design stage) will not change the results, which will be discussed in the following. The assessment by the hot-spot concept is displayed in Fig. 14 and by the notch stress concept in Fig. 15. The calculated fatigue life curves for both concepts, which are valid for the failure criterion total rupture and $\mathrm{P}_{\mathrm{s}}=97.7 \%$, cover all results for the comparable failure criterion break-through. Even the results for the criterion crack initiation of a crack with the depth of a $\approx 1.00 \mathrm{~mm}$ are on the safe side with one exception. The curves with $\mathrm{P}_{\mathrm{s}}=97.7 \%$ for the experimental results are derived from the experimental mean curves with $\mathrm{P}_{\mathrm{s}}=50 \%$ using the factor $\mathrm{j}=1.37$ as explained in Fig. 8. As the insertion of the particular experimental curves with $\mathrm{P}_{\mathrm{s}}=97.7 \%$ into the Figs. 14 and 15 would overload them, they are not presented here but used later for the comparison of the calculated fatigue lives with the experimental ones.

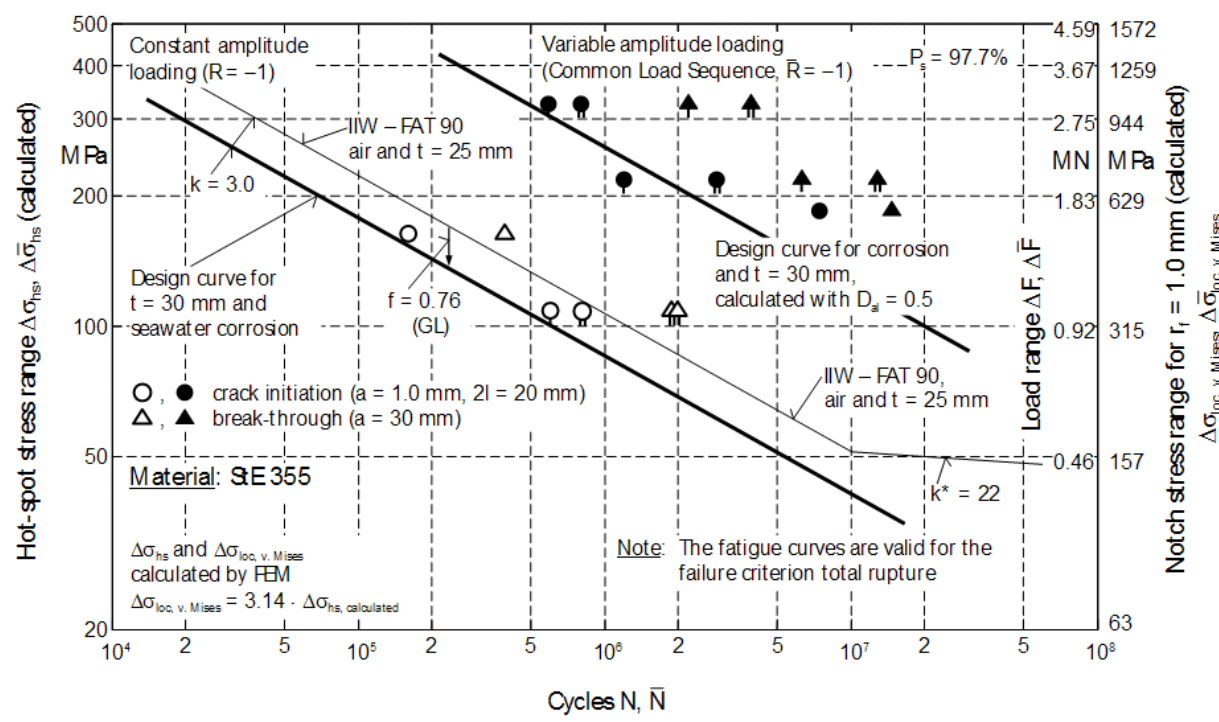

Figure 14: Application of the hot-spot concept for the evaluation of welded K-nodes. 


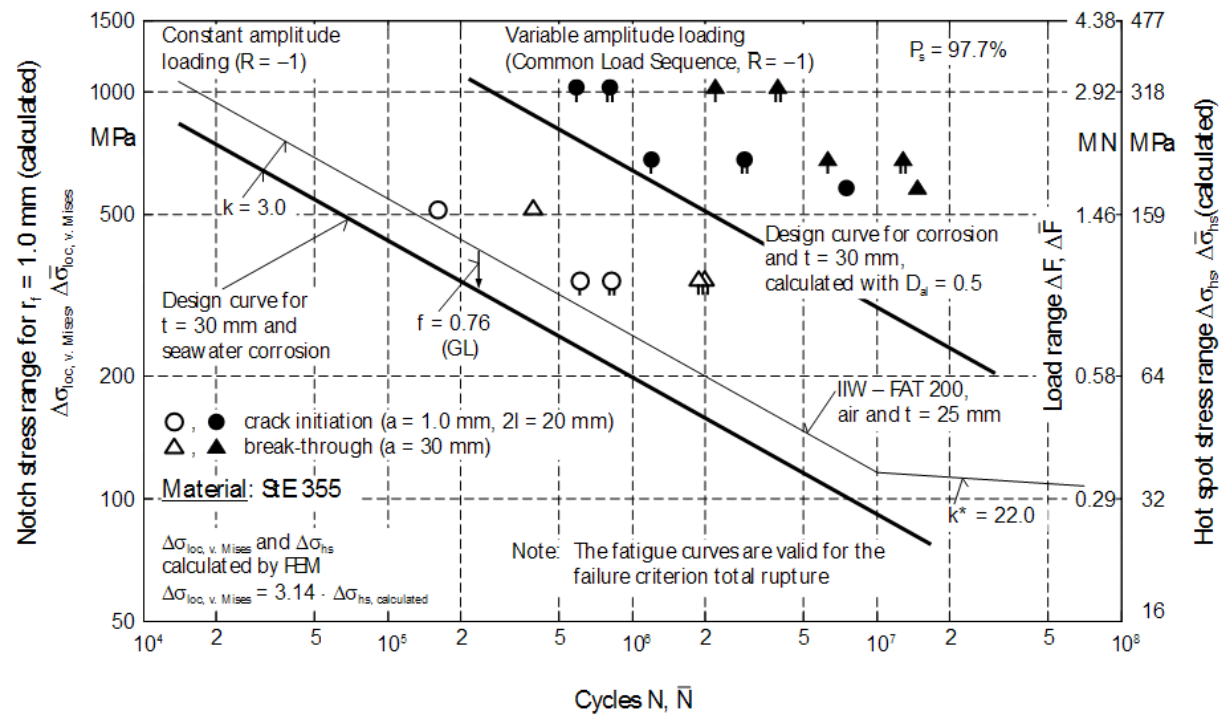

Figure 15: Application of the notch stress concept with $\mathrm{r}_{\mathrm{ref}}=1.0 \mathrm{~mm}$ for the evaluation of welded K-nodes.

The crack propagation lives, calculated as well as measured from a crack depth of $a \approx 1.00 \mathrm{~mm}$ to break-through, are presented in Fig. 16. As the calculations were carried out with the Paris-Erdogan law for the probability of survival of $\mathrm{P}_{\mathrm{s}}=$ $50 \%$, Fig. 11, they are compared with the experimental mean curves. Here also, the calculations lie on the safe side. Besides this, they reveal that the cracks propagate slowly and permit their detection by inspections before break-through.

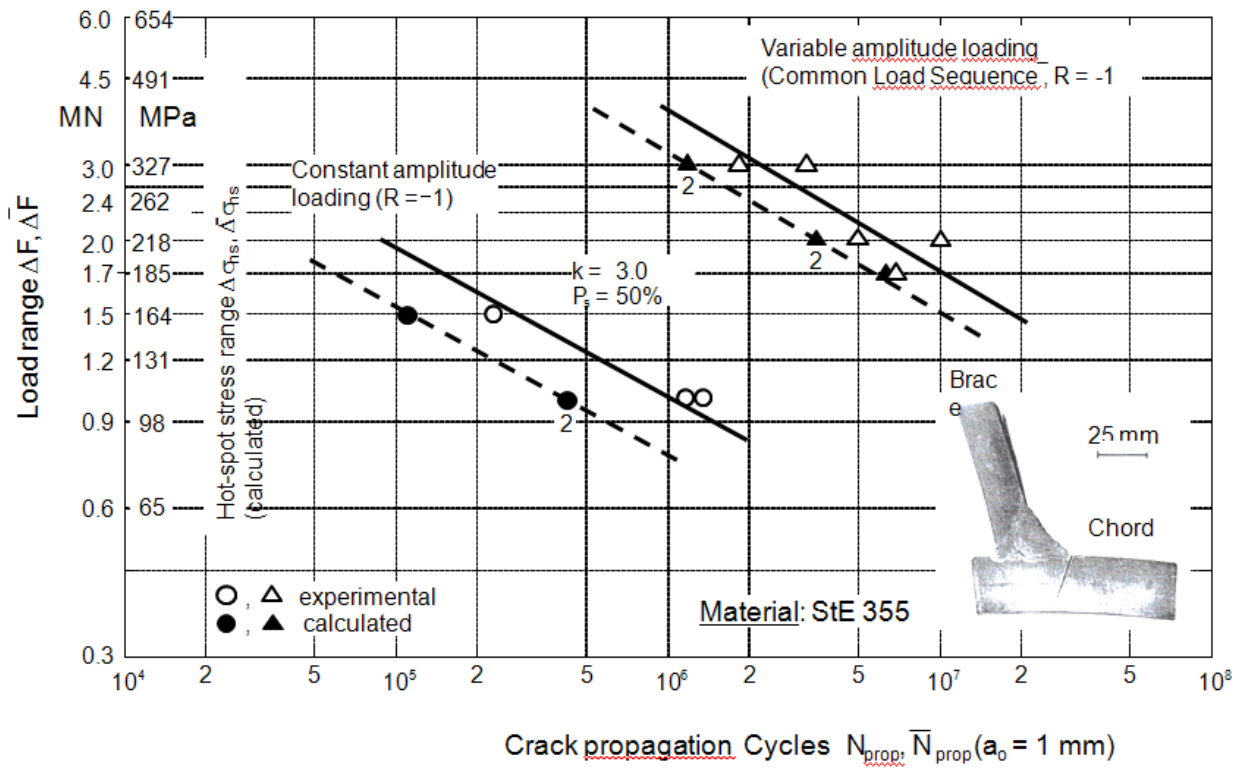

Figure 16: Comparison of experimental and calculated crack propagation lives.

The accuracy of the concepts can be evaluated by the ratio between the calculated and experimental fatigue lives, Fig. 17 . On the basis of the assumptions and prerequisites described already, the hot-spot and crack-propagation concepts reveal the same accuracy. However, the notch stress concept with the reference radius $r_{r e f}=1.00$ is more conservative. But this may result from the modelling of the weld. Also for the crack propagation concept, it has to be mentioned again that the crack propagation was calculated with $\mathrm{R}=0$ conservatively. Nevertheless, all three concepts do not exaggerate on the safe side and are reliable. 


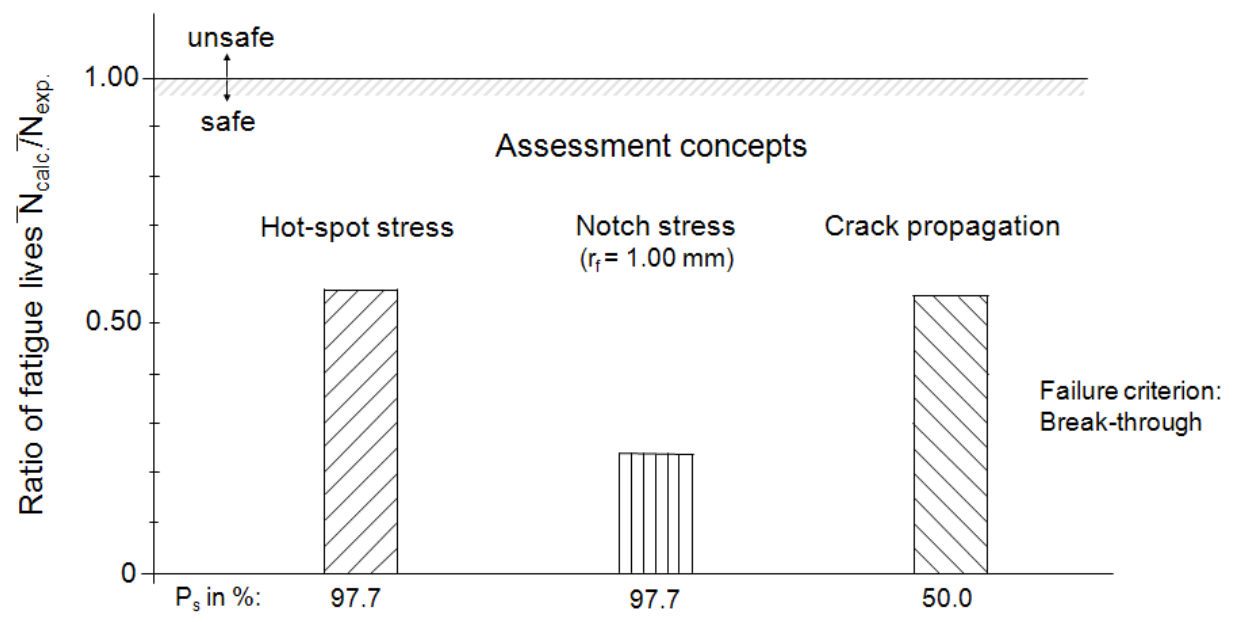

Figure 17: Accuracy of fatigue life estimations according to different concepts by the example of welded K-nodes.

\section{CONCLUSIONS AND SUMMARY}

$\mathrm{T}$

he applied local concepts show similar results. The observed differences in the results are certainly due to the particular assessments but still tolerable and support the overall evaluation of the structural durability behaviour of the K-nodes, i.e. for assessing the safety of a structure the parallel application of different concepts, their reliably provided, assures the evaluation. In this context good balance between calculations, experimental verifications and feedbacks from field service, Fig. 18, lead to a reliable design.

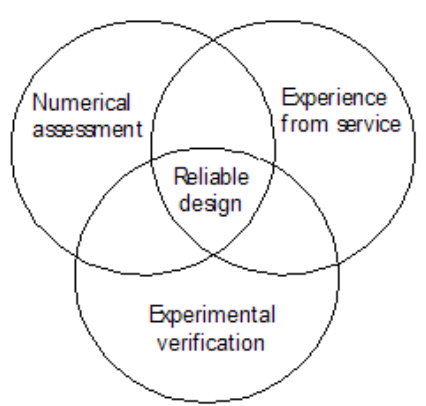

Figure 18: Knowledge interaction for reliable design.

\section{REFERENCES}

[1] C.M. Sonsino, Mat.-wiss.u. Werkstofftech. 38-1 (2007) 9.

[2] D.Radaj, C.M. Sonsino, W. Fricke, Fatigue Assessment of Welded Joints by Local Approaches Woodhead Publishing, Cambridge, (2006) $2^{\text {nd }}$ Edition.

[3] Corrosion Fatigue of Welded Tubular Joints and Cast-Steel Compound Tubular Joints in Large Size Scale Report No. EUR 14316 DE, Brussels, European Coal and Steel Commission (1993).

[4] A.Hobbacher (Ed.), Recommendations for Fatigue Design of Welded Joints and Components IIW Doc. No. XIII1823-07 (update July 2008).

[5]. Rules for Classification and Construction Offshore Technology, Part 2 Offshore Installations Structural Design, Section 3 G: Fatigue Germanischer Lloyd, Hamburg (1990).

[6] C.M. Sonsino, Suggested Allowable Equivalent Stresses for Fatigue Design of Welded Joints According to the Notch Stress Concept with the Reference Radii $r_{\text {ref }}=1.00$ and 0.05 mm IIW-Doc. No. XIII-2216-08 / XV-1285-08, Graz (2008). 
[7] E. Haibach, Betriebsfestigkeit: Verfahren und Daten zur Bauteilberechnung Springer-Verlag, Düsseldorf (2003) $2^{\text {nd }}$ Edition.

[8] C .M. Sonsino, Int. J. Fatigue 29 (2007) 1080.

[9] C.M. Sonsino, M. Vormwald, Geschweißte Offshore - Rohrknoten (Anwendungsbeispiel) In: Bruchmechanischer Festigkeitsnachweis für Maschinenbauteile (FKM), Frankfurt (2004) 81.

[10] D. Radaj, C.M. Sonsino, D. Flade, Int. J. Fatigue 20-6 (1998) 471.

[11] W. Fricke, Guideline for the Fatigue Assessment by Notch Stress Analysis for Welded Structures IIW-2240r1-08 / XV-1289r1-08 (2008). 